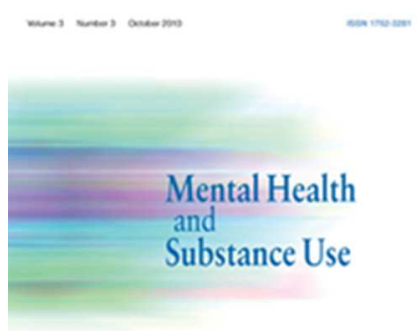

Reocosese

\title{
Key performance indicators for mental health and substance use disorders: \\ a literature review and discussion paper
}

\begin{tabular}{|r|l|}
\hline Journal: & Mental Health and Substance Use \\
\hline Manuscript ID: & RMHS-2014-0001.R1 \\
\hline Manuscript Type: & Review \\
\hline Keywords: & $\begin{array}{l}\text { service, treatment outcome, comorbidity, service provision, dual diagnosis, } \\
\text { substance use }\end{array}$ \\
\hline \multicolumn{2}{|c}{} \\
\hline
\end{tabular}

\section{SCHOLARONE ${ }^{m}$}

Manuscripts 


\title{
Key performance indicators for mental health and substance use disorders: a literature review and discussion paper
}

\begin{abstract}
With increasing recognition of the importance of mental and substance use disorders for population health and health systems and the potential value of systems-based performance indicators in addressing this issue, we aimed to describe the development and content of key performance indicators for mental and substance use disorders. Publications were identified through official websites, Google searches and PubMed. Following 'PRISMA' guidelines, twenty-five studies were kept for qualitative synthesis and six for quantitative analysis. We describe their use in practice by comparing their application across a range of public and mixed healthcare systems. Currently, key performance indicator development for mental and substance use disorders adopts several methodologies, including expert opinion, literature review, stakeholder consultation and the structured consensus method. The rationales provided for selection of particular key performance indicators vary greatly between systems. Systems exhibit different levels of key performance indicator adaptability, which is reflective of dynamic changes in evidence-based practices. We noted bias in the level of key performance indicator assessment towards system/health plan evaluation followed by programme/service evaluation. Similarly, there is a large skew towards key performance indicators that reflect evaluation of processes. Collection of data in all systems is nearly exclusively reliant on electronic administrative/medical data. Experiences from these systems are synthesized into methodological recommendations, and considerations for further research and clinical practice are provided.
\end{abstract}

Key words: Performance indicators, mental health, substance-related disorders -1 - 


\section{Key performance indicators for mental health and substance use disorders: a literature review and discussion paper}

\section{Introduction}

Over 450 million people are afflicted worldwide with neuropsychiatric conditions (World Health Organisation, 2001). Five of the ten leading causes of death and disability globally are attributable to mental and substance use disorders (MESUDS) (World Health Organisation, 2002). Furthermore, the measureable social and economic costs of MESUDS to the individual, society and economy are extensive at approximately 3-4\% of Gross Domestic Product (GDP) (International Labour Organisation, 2000). Above and beyond the explicit health, social services and reduced productivity costs are the implicit consequences, especially impact on individuals, their families and society (World Health Organisation, 2001).

There is established literature documenting the co-morbid nature of MESUDS (Anderson \& Baumberg, 2006; Grant et al., 2004; Jane-Llopis \& Matytsina, 2006; Merikangas et al., 1998; Rohde, Lewinsohn, \& Seeley, 1991). This has implications for diagnosis, treatment and continuity of care in that, individuals with depressed mood states are more likely to smoke and drink, less likely to quit, and more likely to relapse after cessation (Kenney et al., 2009). Negative health consequences as a result of underestimating or not recognizing the co morbid nature of MESUDS has also been described (Staiger, Richardson, Long, Carr, \& Marlatt, 2013). Thus, it is reasonable to consider optimised comprehensive health care for MESUDS a priority. 
Reflecting this emerging need for optimization of health care for MESUDS are new policy and implementation initiatives seen at multiple levels of healthcare. Actively flexible policies and health care structures that enable accessible community-based health care, which are delivered through evidence-based integrated multidisciplinary approaches addressing the biological, psychological and social factors contributing to MESUDS, are becoming more widely reported (Government of Ireland, 2006; Health Canada, 2002; NHS Department of Health, 2012; Pawsey, Logan, \& Castle, 2011; Watkins \& Pincus, 2011). Furthermore, in order to maximize limited resources and address the gap between evidence-based best healthcare practices and the care that is actually received, health systems need to address the underdevelopment of their infrastructure, both at local and national levels, thus enabling measurement of system performance (Hermann et al., 2002; Institute of Medicine, 2001) using measures which are both valid and reliable (Hermann et al., 2000). Such performance measurement is likely to be integral to active evolution of a health system to meet the needs of its users, may form the foundation for accountability and provision of good quality care (Hermann et al., 2004; Pincus et al., 2007) and has contributed to the development, content and application of key performance indicators (KPIs) for MESUDS for several health systems internationally (Hermann et al., 2006; Watkins \& Pincus, 2011).

The development of KPIs for MESUDS firstly requires a performance management system created for continuous quality improvement; therefore, the system must have the means, capability and infrastructure to conduct performance reviews, which lead to sequential recalibration of organizational goals and achievement strategies (i.e. be sensitive, and reactive to achievement or failure to reach intended predetermined 
goals). Ideally, the system should also be capable of determining if other parameters are being influenced/factors are influencing the desired outcomes. Consequently, a performance management system must have set strategic aims, goals and objectives and corresponding implementation plans outlined to achieve those aims, goals and objectives (McEwan \& Goldner, 2001). These are necessary as KPIs are intended to represent the progress towards specified objectives. The actual selection process of indicators is highly system-dependent; the number of indicators must be sufficient to address the objectives, yet not inundate the system such that it detracts from meaningful interpretation (McEwan \& Goldner, 2001). Likewise, target setting must be appropriately based on past performance information, or comparable systems in other jurisdictions (McEwan \& Goldner, 2001).

Assessment of individual KPIs against specified criteria may assist in choosing an appropriate set for a given system (McEwan \& Goldner, 2001). Glover and KamisGould (Glover \& Kamis-Gould, 1996) suggested nine criteria for good performance indicators: “(1) Conceptual clarity, (2) Clear link to an organizational goal, (3) Operationally defined, reliable and valid measures, (4) Measures derived wherever possible from available management information systems, (5) Consisting of proportion and ratios rather than raw numbers, (6) Desired direction for performance is clear, (7) Indicators suitable for comparison (risk adjusted where necessary), (8) Sufficiently universal for comparison with other services, and (9) Decision rules for significant deviations from chance and for establishing high and low performance." These criteria were reflected by Hermann and Palmer (Hermann \& Palmer, 2002) in their developmental framework for quality measures specifically for MESUDS care. Monitoring, compilation and reporting of performance parameters requires that 
information: be collected in a routine manner using devoted resources; be relevant and appropriate to the systems' aims, goals and objectives; and be readily disseminated to stakeholders (McEwan \& Goldner, 2001). Making performance reports publicly available can promote system accountability and may identify outlying practices, thus allowing appropriate intervention (e.g., remediation or reward) (Canadian Institute of Health Information, 2013; McEwan \& Goldner, 2001). Finally, realigning the performance framework to reflect changing aims and objectives, as well as to address under or over performance, reflects the cyclical nature of a sound performance system's use of KPIs (McEwan \& Goldner, 2001).

The purpose of this paper is to describe the development and content of KPIs for MESUDS and to describe their use in practice. For this purpose, their application across exemplar public and mixed healthcare systems was examined.

\section{Methods}

An initial search identified systems that had reported extensively on performance measures; from which four systems were selected that would represent a range of funding and delivery arrangements for comparison purposes. Examples of mixed (private delivery / publicly funded) systems included Ireland's Health Services Executive (HSE) and Canada's 'Medicare', while examples of public systems included United States Veterans Health Administration (VHA) and the UK National Health Service (NHS). It should be noted that Canada's 'Medicare' is an example of a health system that is administrated provincially; therefore, 'Canada' henceforth refers to a synthesis of provincial level findings provided by Canadian publications but does 
not necessarily reflect national findings per se. Although we sought to include a private health care system for inclusion in this comparison, we were unable to identify such a system that had reported on the development and application of performance measures for MESUDs in the public domain.

Publications concerning development, content and application of KPIs for MESUDS for public, private and mixed healthcare systems, written in the English language, were identified through official websites, Google searches (June 29, 2012) and PubMed (July 24, 2012) (see Table 1) with no limitation on date range of publications. Following 'PRISMA' guidelines (Moher, Liberati, Tetzlaff, Altman, \& Grp, 2010), 384 unique papers were identified through these sources using the terms, including MeSH terms, outlined in Table 1, 108 papers were retained based on title screening and 36 were retained after assessment of full-text abstracts screening. Twenty-five studies were kept for qualitative synthesis and six for quantitative analysis (Table 2). All articles were retained that did not meet any of the following reasons for exclusion:

- Population did not have a DSM-IV axis 1 condition

- Did not discuss either the development, content or application of KPIs

- Did not represent one of the four jurisdictions (ie. Canada, NHS, HSE, VHA)

$$
\begin{aligned}
& \text { <insert Table } 1 \text { here }> \\
& \text { <insert Table } 2 \text { here }>
\end{aligned}
$$

Individual performance measures from the four representative health systems were classified by the method outlined by Lauriks et al (Lauriks, Buster, de Wit, Arah, \& Klazinga, 2012). A total of six government publications outlined unique KPIs from

$$
-6-
$$


the systems (Table 2). In the case where specific classifications for a given characteristic were not reported in the publication, the author $(\mathrm{CH})$ classified the KPIs using both the definitions of characteristics provided (McEwan \& Goldner, 2001) (Table 3) and similarly stated KPIs from other publications in which classification was provided.

<insert Table 3 here $>$

The six key government publications, which are used to illustrate KPIs for MESUDs in this discussion paper, are outlined in Table 2. The rest of the publications included in this discussion paper are used in the text to compare and describe the main features of the four-exemplar systems.

\section{Results}

\section{Use in practice: comparing application across specific systems}

Canada, HSE, NHS and VHA all employ KPIs spanning various domains (refer to Table 2). Canada's 'Medicare', which represents a synthesis of provincially based systems, and VHA have used a mixed-methods approach to KPI development. Specifically, for each KPI, a literature review followed by expert consultation for Canada and a tri-step approach of literature review, stakeholder consultation and structured consensus for the VHA. The HSE and NHS used a singular approach, consisting of expert opinion and stakeholder consultation, respectively.

These systems have an inherent bias in the level of assessment that KPIs evaluate; the bias is towards system/health plan evaluation followed by programme/service 
evaluation (Table 2). Similarly, there is a large skew towards KPIs that reflect process evaluation (i.e. key activities which relate to provision of care such as implementation of best-practice care, and service contacts in terms of client visits/admissions, etc.). Most systems employ a generalist approach to the diagnoses that a given KPI for MESUDS encompasses. Collection of data in all systems is nearly exclusively reliant on electronic based administrative/medical data; this is particularly the case with the HSE whereby it only collects data on in-patients, as it is the only electronic information gathering system currently in place. Canada is the exception to this, as it accommodates a region's decision to either collect administrative/medical data or to use surveys in either paper or electronic formats. Also, the VHA does allow for some paper data collection through its External Peer Review Program chart audit process.

With respect to the parameters of performance that KPIs evaluate, Canada places particular emphasis on competence, albeit the precise way in which to evaluate this is still emerging (McEwan \& Goldner, 2001). Other foci include appropriateness (ie. evidence of best-practice core programs, treatment protocols for co-morbidity, etc.), accessibility (ie. access to primary care, access to psychiatrists, etc.) and effectiveness (ie. community tenure, potential years of life lost, etc.) (refer to Table 2). Similarly, the other mixed health care example, the HSE, has accessibility and appropriateness as their main focus areas for KPIs. The public health care examples of the NHS and VHA differ in their main performance metrics in that for the NHS, efficiency and accessibility are mainstays whereas the VHA is fairly balanced across all dimensions, but is missing KPIs for efficiency (Table 1); though some of the KPIs used by VHA may also infer efficiency (Watkins \& Pincus, 2011). However, the provided 
definitions of those KPIs do not meet this study's criteria for being a KPI, which represents the efficiency domain as outlined in Table 3. Lastly, it is important to note that although this study aimed to provide a private health care example for KPIs, there was no publicly available information accessible on official websites to do so.

\section{Development and content of KPIs for MESUDS}

While developing KPIs based on expert opinion alone is suboptimal compared to other development methods due to lack of evidence/justification and bias (Lauriks et al., 2012), this approach requires the least resources and may be helpful as an initial starting point in developing a set of KPIs. Alternatively, a system may choose to adapt KPIs utilized in another system to their own needs; however, this can be fraught with obstacles such as lack of sufficient fiscal, organisational, infrastructural and personnel resources to appropriately collect KPIs and ensure dissemination of findings (Garnick, Lee, Horgan, Acevedo, \& Washington Circle Public, 2009). As the System progresses, there are ample literature resources providing structure and guidance for using more robust methods, which enhance KPI development through collaboration, applying pre-existing instruments and consulting with key stakeholders (Addington, Kyle, Desai, \& Wang, 2010; Baars, Evers, Arntz, \& van Merode, 2010; Lauriks et al., 2012; Lin \& Durbin, 2008; Rush, Martin, Corea, \& Rotondi, 2012). One such example of this is the Resident Assessment Instrument for Mental Health (interRAI MH), which is an assessment system providing information on care planning, case-mix and outcomes, that has been used to derive mental health quality indicators (Perlman et al., 2013). Establishing a collaborative process is integral in the development of KPIs as MESUD academics, clinicians, consumers and decisionmakers will differ in their opinion of what KPIs are of most importance (Waraich et 
al., 2010). The structured consensus is ultimately the most rigorous development method for KPIs; however, this, in itself, requires sufficient resources and infrastructure to execute, such that it is the least used development method for MESUD KPIs (Lauriks et al., 2012; Waraich et al., 2010; Watkins \& Pincus, 2011).

Irrespective of the development method chosen, some systems provide comprehensive rationale for selecting a particular KPI. For example, in many Canadian documents, a succinct rationale statement followed by literature justification, where applicable, is offered for each KPI (Alberta Health Services, 2010; McEwan \& Goldner, 2001). The VHA refers the reader to an entire chapter devoted to rationale (Watkins \& Pincus, 2011). It is integral to KPI development that justification and well-defined criteria for both indicator type and target population are provided; the lag in development of MESUD KPIs is attributable to poorly-defined indicators (Kilbourne, Keyser, \& Pincus, 2010). Absence of clear definitions is a challenge and particularly hinders development involving stakeholder consultation and structured consensus, with key terms open to interpretation (see Table 2 for the definitions used in this study). Furthermore, it impedes the ability of other parties to accurately assess KPIs and draw conclusions across Systems as it makes classification (e.g., Table 1) open to interpretation.

Having an appropriate representation of KPIs for the three care domains (i.e. structure/input, process and outcome) helps to ensure a balanced perspective of a system's performance as the rationale behind these three domains is that structure influences resources and policies which, in turn, informs clinician care processes that ultimately impact patient outcomes (Kilbourne et al., 2010). Indicators of each 
domain have inherent strengths and limitations that must be effectively balanced (Kilbourne et al., 2010):

- Indicators of structure, although the most straightforward to ascertain through programme leader reports are, by their reporting nature, at risk of response bias (Kilbourne et al., 2010). Furthermore, a structure indicator can only reflect capacity for appropriate care and is not capable of determining if the actual care takes place (Kilbourne et al., 2010).

- Process indicators, which are the most commonly used as they represent aspects of care that systems have the most control over, can be overly dependent on a patient's attendance at appointments as data sources do not typically record the reason for missed appointments (Kilbourne et al., 2010). For example, if the patient did not attend a follow-up appointment this can reflect a process problem in that it was a failure of the visit to be scheduled by the provider or, alternatively, the patient simply missing the appointment can skew this indicator. Furthermore, differentiation of event-driven and paneldriven process indicators is important in order to glean corresponding information related to specific care events and management of a patient within the system. Continuing research into improvements in risk adjustment for process indicators, such as restraint use in mental health services, is adding to their robustness as KPIs (Perlman et al., 2013).

- Outcome measures, which reflect change in patient status are also appealing to Systems (Kilbourne et al., 2010). The main challenge encountered with outcome measures is case-mix adjustment, which needs to be taken into consideration to ensure that observed differences in outcomes are not due to clinical difference in illness severity across patients (Kilbourne et al., 2010). 
This effect is readily seen between a comparison of outcome measures from systems that treat populations which are clinically recognized as being more severely afflicted than Systems that treat less clinically severe populations (Leslie \& Rosenheck, 2000). Currently, the ability for risk adjustment is limited and needs to be taken into consideration when analyzing outcome indicators (Kilbourne et al., 2010).

Another premise emerging in KPIs development for MESUDS is the recognition by many Systems, which jointly evaluate these co-morbid conditions, that there is a bias towards KPIs for mental disorders, while KPIs for substance use disorders lag behind (National Treatment Strategy Working Group, 2008). Canada and the VHA are actively addressing this gap whilst providing a framework for other systems that currently do not integrate the two classes of disorders for performance measurement (National Treatment Strategy Working Group, 2008; Thomas et al., 2011; Watkins \& Pincus, 2011). In addition to the realization that optimal care for mental and substance use disorders involves integration, it is also increasingly being acknowledged by many systems that delivery of this integrated optimal care needs to be established in the primary care setting (Addington et al., 2010; Government of Ireland, 2006; Health Canada, 2002; Sandoval, Couris, \& Leeb, 2012; Watkins \& Pincus, 2011). This change in focus means that indicators which were once designed to measure at the institutional level must now also be reflective of the community level (Sandoval et al., 2012). All of this best practice information has created a substantial change in the structure of mental and substance use disorder care delivery in Canada and the VHA, and has also persuaded Ireland's HSE to consider a similar restructuring from inpatient to outpatient primary care services (Government of 
Ireland, 2006).

This restructuring of care delivery has fostered the rapid development and use of electronic systems for administration and medical data management which has correspondingly enabled highly efficient collection of information for KPIs (Health Canada, 2002; NHS Department of Health, 2012; Watkins \& Pincus, 2011). The electronic system facilitates the generation of ratios, as opposed to just raw number collection, which is regarded as preferable for KPIs reporting (McEwan \& Goldner, 2001). The Canadian Institute of Health Information is one such example of electronic web-based reporting which allows data collection from more than sixhundred facilities across all provinces in Canada involved in many aspects of health care (Canadian Institute of Health Information, 2013). With this heavy reliance on automated data collection, caution is warranted in that patient perspectives, often represented by the domain 'acceptability' in Table 2, may not be effectively captured as this data is often collected via survey/audit (Koch, Breland, Nash, \& Cropsey, 2011). Furthermore, uploading of diagnosis-based events may not capture more subtle interventions within the encounter. The utility of patient responses in improving quality of services, which leads to improved outcomes, cannot be neglected.

\section{Discussion}

This review was solely focused on KIPs from the four jurisdictions of Canada, HSE, NHS and VHA. In general, this study's results for MESUDS KPIs are in line with the relationships previously outlined by other studies evaluating KPIs for mental health 
(Baars et al., 2010; Lauriks et al., 2012). There are no major discrepancies in the indicators used; the majority of KPIs assess care processes and outcomes, are applicable to general diagnoses, and can be collected through administrative data (Baars et al., 2010; Lauriks et al., 2012). Although similar relationships have been identified, there are likely differences in the raw number classifications in Table 2 as compared to the similar analysis performed by Lauriks et al (Lauriks et al., 2012) for mental health indicators. The differences would be attributable to variation in definitions used for classification of KPIs.

This highlights that lack of key accepted definitions is one of the reasons why KPI development for MESUDS lags behind other conditions (Addington et al., 2010; Baars et al., 2010; Kilbourne et al., 2010; Waraich et al., 2010). KPI targets for MESUDS continue to vary across the different systems, reflecting the respective local definitions and interests of the systems (Lauriks et al., 2012). Similarly, most systems have provided some evidence for the content validity of their KPIs, but reliability and criterion/construct validity are rarely assessed (Lauriks et al., 2012). Specific to outcome measures, the challenge of case-mix adjustment remains. This needs to be taken into consideration to ensure that observed differences in outcomes are not due to clinical difference in illness severity across patients (Kilbourne et al., 2010). Furthermore, transparency of reporting continues to be an issue for private systems which hinders not only the advancement of MESUD KPI development, but also has arguably a negative impact on the care, in terms of effective treatment in the acute and long term, practitioner contacts and hospital admissions, that is received by patients in a private system (Druss, Miller, Rosenheck, Shih, \& Bost, 2002). 
Based on this review of the Canadian, HSE, NHS and VHA systems, we suggest a six-step approach to developing and refining KPIs for MESUDS, which could include:

- Identify resources (fiscal, organizational, infrastructural and manpower) which are available to support MESUDS KPI development, collection and analysis.

- Outline specific aims, goals and objectives of the system, given the aforementioned resources or specific idealized aims, goals and objectives and corresponding resources that would be required to facilitate those idealizations. This needs to be considered within the context of existing infrastructure, degree of systems integration across and within the health care spectrum and payor mix and other external drivers.

- Define key terms to be used and the target population(s).

- Conduct structured collaborative processes, within the means of the system, to outline KPIs that reflect aims, goals and objectives of key stakeholders.

- For each KPI, consider: rationale / evidence base, criteria by which under / over performance will be determined / addressed and validation mechanism.

- Establish a timely system framework review process with recommendations for changes/updates to reflect developing literature and needs of the population

This review was solely focused on KIPs from the four jurisdictions of Canada, HSE, NHS and VHA. The search was limited PubMed databases, google searches and direct website searches all in the English language. We acknowledge that this review discusses major government reports. PRISMA guidelines allowed for establishment of an orderly and thorough search of these resources. Only one person screened for 
eligibility and data extraction; although this does lend to consistency as it was the same person for both. The main strength of this study is that it provides comprehensive information on KPI development, content and application for both mental health and substance use disorders through exemplar systems; this creates a framework for future improvements in KPIs for MESUDS.

\section{Conclusions}

Although a comparison between systems' use of types of KPIs was drawn, it is important to recognize that systems have unique foci, which means that the data generated by these types of KPIs may not be universally applicable or comparable between systems, unlike the types of KPIs. For example, a commonly used KPI for MESUDS in many systems is hospital re-admission rate; in a system like the HSE, whereby the majority of MESUD care is delivered through an in-patient model, it is correspondingly going to have a higher re-admission rate as compared to a system that delivers care through an outpatient model, such as many of the provinces in Canada. The numerical difference in hospital re-admission rate between these systems is not a meaningful comparison since the system design varies. KPIs allow for meaningful "within-system" or intrasystem evaluations of data, but caution is needed by researches when embarking on intersystem comparisons of performance using data generated by KPIs. KPIs can be useful at a system, practice or individual level depending upon the indicator, denominator and metric.

To optimise MESUDS performance measurement for the future, there needs to be well defined parameters/descriptions of KPIs established in the literature, 
improvements in the research base, and clinical implementation of evidence-based practices for optimal care. In support of this, there needs to be development from the information technology sector of cost effective solutions to address the challenges facing systematic implementation of electronic infrastructure. Emerging from these improvements could be the capabilities for validation and potentially 'pre-validation' (Harris, Kivlahan, Bowe, Finney, \& Humphreys, 2009) with predictive algorithms for KPIs which would complete the optimisation of comprehensive health care for MESUDS. 


\section{Authors' contributions}

$\mathrm{CH}$ participated in the design of the study, performed the literature review, classified the findings and drafted the manuscript. JK participated in the design of the study and contributed to the manuscript. CD, DL, DM, TOT contributed to the manuscript. WC conceived of the study, participated in its design and coordination and contributed to the manuscript. All authors read and approved the final manuscript.

\section{Acknowledgements}

$\mathrm{CH}$ would like to acknowledge the Graduate Entry Medical School at the University of Limerick for providing this studentship opportunity.

\section{Competing interests}

The authors declare that they have no competing interests.

\section{Ethical approval}

Research described in this manuscript adheres to international ethical standards; we conducted a review of literature for which no approval from a named research ethics committee was required.

$-18-$ 


\section{References}

Addington, D., Kyle, T., Desai, S., \& Wang, J. L. (2010). Facilitators and barriers to implementing quality measurement in primary mental health care systematic review. Canadian Family Physician, 56(12), 1322-1331.

Alberta Health Services. (2010). System level performance for mental health and addiction in alberta 2008/2009. Edmonton, AB: Alberta Health Services.

Anderson, P., \& Baumberg, B. (2006). Alcohol in europe: A public health perspective. London, UK: Institute of Alcohol Studies.

Baars, I. J., Evers, Smaa, Arntz, A., \& van Merode, G. G. (2010). Performance measurement in mental health care: Present situation and future possibilities. International Journal of Health Planning and Management, 25(3), 198-214. doi: $10.1002 / \mathrm{hpm} .951$

Canadian Institute of Health Information. (2013). Canadian institute of health information, from http://www.cihi.ca

Druss, B. G., Miller, C. L., Rosenheck, R. A., Shih, S. C., \& Bost, J. E. (2002). Mental health care quality under managed care in the united states: A view from the health employer data and information set (hedis). American Journal of Psychiatry, 159(5), 860-862. doi: 10.1176/appi.ajp.159.5.860

Garnick, Deborah W., Lee, Margaret T., Horgan, Constance M., Acevedo, Andrea, \& Washington Circle Public, Sector. (2009). Adapting washington circle performance measures for public sector substance abuse treatment systems. Journal of Substance Abuse Treatment, 36(3), 265-277. doi: 10.1016/j.jsat.2008.06.008

$-19-$ 
Glover, G., \& Kamis-Gould, E. (1996). Performance indicators in mental health. In G. Thornicroft \& G. Strathedee (Eds.), Commissioning mental health services. London: HMSO.

Government of Ireland. (2006). A vision for change: Report of the expert group on mental health policy. Dublin: Stationary office.

Grant, B. F., Stinson, F. S., Dawson, D. A., Chou, S. P., Ruan, J., \& Pickering, R. P. (2004). Co-occurrence of 12-month alcohol and drug use disorders and personality disorders in the united states - results from the national epidemiologic survey on alcohol and related conditions. Archives of General Psychiatry, 61(4). doi: 10.1001/archpsyc.61.4.361

Harris, A. H. S., Kivlahan, D. R., Bowe, T., Finney, J. W., \& Humphreys, K. (2009). Developing and validating process measures of health care quality an application to alcohol use disorder treatment. Medical Care, 47(12), 12441250.

Health Canada. (2002). Best practices: Concurrent mental health and substance use disorders. Ottawa, ON: Health Canada.

Hermann, R. C., Finnerty, M., Provost, S., Palmer, R. H., Chan, J., Lagodmos, G., . . Myrhol, B. J. (2002). Process measures for the assessment and improvement of quality of care for schizophrenia. Schizophr Bull, 28(1), 95-104.

Hermann, R. C., Leff, H. S., Palmer, R. H., Yang, D., Teller, T., Provost, S., . . . Chan, J. (2000). Quality measures for mental health care: Results from a national inventory. Med Care Res Rev, 57 Suppl 2, 136-154.

Hermann, R. C., Mattke, S, Somekh, D, Silfverhielm, H, Goldner, E, Glover, G, . . . Chan, J A. (2006). Quality indicators for international benchmarking of mental $-20-$ 
health care. International Journal for Quality in Health Care, 18(suppl 1), 3138.

Hermann, R. C., Palmer, H., Leff, S., Shwartz, M., Provost, S., Chan, J., . . . Lagodmos, G. (2004). Achieving consensus across diverse stakeholders on quality measures for mental healthcare. Med Care, 42(12), 1246-1253.

Hermann, R. C., \& Palmer, R. H. (2002). Common ground: A framework for selecting core quality measures for mental health and substance abuse care. Psychiatr Serv, 53(3), 281-287.

Institute of Medicine. (2001). Crossing the quality chasm: A new health system for the 21st century. Washington, DC: National Academies Press.

International Labour Organisation. (2000). Mental health in the workplace. Geneva: International Labour Organisation (ILO).

Jane-Llopis, E., \& Matytsina, I. (2006). Mental health and alcohol, drugs and tobacco: A review of the comorbidity between mental disorders and the use of alcohol, tobacco and illicit drugs. [Review]. Drug and Alcohol Review, 25(6), 515-536. doi: $10.1080 / 09595230600944461$

Kenney, B. A., Holahan, C. J., Holahan, C. K., Brennan, P. L., Schutte, K. K., \& Moos, R. H. (2009). Depressive symptoms, drinking problems, and smoking cessation in older smokers. Addict Behav, 34(6-7), 548-553. doi: 10.1016/j.addbeh.2009.03.020

Kilbourne, A. M., Keyser, D., \& Pincus, H. A. (2010). Challenges and opportunities in measuring the quality of mental health care. Canadian Journal of Psychiatry-Revue Canadienne De Psychiatrie, 55(9), 549-557.

Koch, J. R., Breland, A. B., Nash, M., \& Cropsey, K. (2011). Assessing the utility of consumer surveys for improving the quality of behavioral health care services. 
Journal of Behavioral Health Services \& Research, 38(2), 234-248. doi: $10.1007 / \mathrm{s} 11414-010-9211-1$

Lauriks, S., Buster, M. C. A., de Wit, M. A. S., Arah, O. A., \& Klazinga, N. S. (2012). Performance indicators for public mental healthcare: A systematic international inventory. Bmc Public Health, 12. doi: 10.1186/1471-2458-12214

Leslie, D. L., \& Rosenheck, R. A. (2000). Comparing quality of mental health care for public-sector and privately insured populations. Psychiatr Serv, 51(5), 650655.

Lin, E., \& Durbin, J. (2008). Adapting the balanced scorecard for mental health and addictions: An inpatient example. Healthcare Policy, 3(4).

McEwan, K., \& Goldner, E. (2001). Accountability and performance indicators for mental health services and supports: A resource kit. Ottawa, ON: Health Canada.

Merikangas, K. R., Mehta, R. L., Molnar, B. E., Walters, E. E., Swendsen, J. D., Aguilar-Gaziola, S., . . Kessler, R. C. (1998). Comorbidity of substance use disorders with mood and anxiety disorders: Results of the international consortium in psychiatric epidemiology. Addictive Behaviors, 23(6). doi: $10.1016 / \mathrm{s} 0306-4603(98) 00076-8$

Moher, D., Liberati, A., Tetzlaff, J., Altman, D. G., \& Grp, Prisma. (2010). Preferred reporting items for systematic reviews and meta-analyses: The prisma statement. International Journal of Surgery, 8(5), 336-341. doi: 10.1016/j.ijsu.2010.02.007

National Treatment Strategy Working Group. (2008). A systems approach to substance use in canada:Recommendations for a national treatment strategy. 
Ottawa, ON: National Framework for Action to Reduce the Harms Associated with Alcohol and Other Drugs and Substances in Canada.

NHS Department of Health. (2012). The nhs performance framework: Implementation guidance. Whitehall, UK: NHS Department of Health.

Pawsey, Brendan, Logan, Greg, \& Castle, David. (2011). Psychological treatments for comorbidity across the life course. Mental Health and Substance Use, 4(1), 72-82. doi: $10.1080 / 17523281.2011 .533456$

Perlman, C. M., Hirdes, J. P., Barbaree, H., Fries, B. E., McKillop, I., Morris, J. N., \& Rabinowitz, T. (2013). Development of mental health quality indicators (mhqis) for inpatient psychiatry based on the interrai mental health assessment. BMC Health Serv Res, 13, 15. doi: 10.1186/1472-6963-13-15

Pincus, Harold Alan, Page, Ann Ex, Druss, Benjamin, Appelbaum, Paul S., Gottlieb, Gary, \& England, Mary Jane. (2007). Can psychiatry cross the quality chasm? Improving the quality of health care for mental and substance use conditions. American Journal of Psychiatry, 164(5). doi: 10.1176/appi.ajp.164.5.712

Rohde, P., Lewinsohn, P. M., \& Seeley, J. R. (1991). Comorbidity of unipolar depression: Ii comorbidity with other mental-disorders in adolescents and adults. Journal of Abnormal Psychology, 100(2). doi: 10.1037/0021$843 x .100 .2 .214$

Rush, Brian, Martin, Garth, Corea, Larry, \& Rotondi, Nooshin Khobzi. (2012). Engaging stakeholders in review and recommendations for models of outcome monitoring for substance abuse treatment. Substance Use \& Misuse.

Sandoval, C., Couris, C., \& Leeb, K. (2012). New mental health indicators provide a snapshot on performance of the mental health system in canada. Healthc $Q$, 15(2), 14-16. 
Staiger, Petra K., Richardson, Ben, Long, Caroline M., Carr, Victoria, \& Marlatt, G. Alan. (2013). Overlooked and underestimated? Problematic alcohol use in clients recovering from drug dependence. Addiction, 108(7), 1188-1193.

Thomas, C. P., Garnick, D. W., Horgan, C. M., McCorry, F., Gmyrek, A., Chalk, M., ... Thatcher, J. (2011). Advancing performance measures for use of medications in substance abuse treatment. Journal of Substance Abuse Treatment, 40(1), 35-43. doi: 10.1016/j.jsat.2010.08.005

Waraich, P., Saklikar, R. S., Aube, D., Jones, W., Haslam, D., \& Hamill, K. (2010). Quality measures for primary mental healthcare: A multistakeholder, multijurisdictional canadian consensus. Quality \& Safety in Health Care, 19(6), 519-525. doi: 10.1136/qshc.2008.027839

Watkins, K., \& Pincus, H. (2011). Veterans health administration mental health program evaluation: Capstone report. Santa Monica, CA: RAND Corporation.

World Health Organisation. (2001). The world health report 2001: New understanding, new hope. Geneva: World Health Organisation.

World Health Organisation. (2002). Reducing risks: Promoting healthy life. World health report 2002. Geneva: World Health Organisation. 
Table 1. Sources of Information

\begin{tabular}{|c|c|c|c|}
\hline \multicolumn{4}{|c|}{ Websites Searched - June 29, 2012} \\
\hline \multirow{10}{*}{\multicolumn{4}{|c|}{$\begin{array}{ll}\text { http://www.gov.bc.ca/health/ } & \text { http://www.health.alberta.ca/ } \\
\text { http://www.health.gov.sk.ca/ } & \text { http://www.gov.mb.ca/health } \\
\text { http://www.health.gov.on.ca/ } & \text { http://www.health.gov.nl.ca/l } \\
\text { http://www.gov.pe.ca/health/ } & \text { http://www.gov.ns.ca/DHW/ } \\
\text { http://www.gnb.ca/0051/index-e.asp } & \text { http://www.hss.gov.yk.ca/ } \\
\text { http://www.hlthss.gov.nt.ca/ } & \text { http://www.hss.gov.nu.ca/en/ } \\
\text { http://www.va.gov/health/default.asp } & \text { http://www.hse.ie/eng/ } \\
\text { http://www.upmc.com/Pages/default.aspx } & \\
\text { http://www.hc-sc.gc.ca/index-eng.php/ } & \\
\text { http://www.nhs.uk/Pages/HomePage.aspx } & \end{array}$}} \\
\hline & & & \\
\hline & & & \\
\hline & & & \\
\hline & & & \\
\hline & & & \\
\hline & & & \\
\hline & & & \\
\hline & & & \\
\hline & & & \\
\hline \multicolumn{4}{|c|}{ Google Search - June 29, 2012} \\
\hline \multicolumn{4}{|c|}{$\begin{array}{l}\qquad \text { [system] substance abuse performance indicator } \\
{[\text { system] mental health performance indicator }} \\
{[\text { system }]=\text { Canada, National Health Service, Health Service Executive, University of }} \\
\text { Pittsburgh Medical Center, Veterans Health Administration }\end{array}$} \\
\hline \multicolumn{4}{|c|}{ PubMed Search Terms - July 24, 2012} \\
\hline Performance & $\mathrm{Hea}$ & System & Population \\
\hline $\begin{array}{l}\text { Benchmarking, health care } \\
\text { [MeSH] OR performance } \\
\text { measure* [ti.ab] OR } \\
\text { performance indicator* } \\
\text { [ti,ab] OR quality } \\
\text { measure* [ti,ab] OR } \\
\text { quality indicator* [ti,ab] }\end{array}$ & $\begin{array}{l}\text { Public hea } \\
\text { private he } \\
\text { mixed hea } \\
\text { canada OF } \\
\text { executive } \\
\text { health ser } \\
\text { veterans C } \\
\text { pittsburgh }\end{array}$ & $\begin{array}{l}\text { care OR } \\
\text { care OR } \\
\text { care OR } \\
\text { ealth service } \\
\text { national } \\
\text { OR } \\
\text { aniversity of } \\
\text { dical center }\end{array}$ & $\begin{array}{l}\text { Mental health* OR mental } \\
\text { disorder OR substance related } \\
\text { disorders }[\mathrm{MeSH}] \text { or addict* }\end{array}$ \\
\hline
\end{tabular}


Table 2. Comparison of Performance Measures for Mental and Substance Use Disorders Across Health Systems (12, 21, 30, 41-43).

Numbers reflect counts of unique key performance indicators for the given classification. Note, raw numbers are not congruent between indicator characteristic categories within a given system example as some KPIs have been assigned to multiple sub-categories.

\begin{tabular}{|c|c|c|c|c|}
\hline \multirow{2}{*}{$\begin{array}{c}\text { Development and } \\
\text { Implementation Characteristics }\end{array}$} & \multicolumn{2}{|c|}{ Mixed Health Care } & \multicolumn{2}{|c|}{ Public Health Care } \\
\hline & Canada & $H S E$ & NHS & $V H A$ \\
\hline \multicolumn{5}{|l|}{ Development method } \\
\hline Expert opinion & 71 & 12 & & \\
\hline Structured consensus & & & & 28 \\
\hline $\begin{array}{l}\text { Mixed literature and } \\
\text { stakeholder }\end{array}$ & & & 21 & 28 \\
\hline $\begin{array}{l}\text { Literature review / application } \\
\text { of pre-existing instruments }\end{array}$ & 71 & & & 28 \\
\hline \multicolumn{5}{|l|}{ Level of Assessment } \\
\hline Client & 15 & & 3 & 5 \\
\hline Service/Program & 38 & 7 & 14 & 20 \\
\hline System/Health plan & 45 & 11 & 14 & 25 \\
\hline \multicolumn{5}{|l|}{ Care domain } \\
\hline Structure/Input & 15 & 2 & 7 & \\
\hline Process & 41 & 6 & 12 & 22 \\
\hline Outcome & 18 & 4 & 3 & 6 \\
\hline \multicolumn{5}{|l|}{ Dimensions of performance } \\
\hline Effectiveness & 11 & 1 & 3 & 6 \\
\hline Accessibility & 12 & 5 & 6 & 3 \\
\hline Acceptability & 7 & & 1 & 5 \\
\hline Competence & 17 & & 1 & \\
\hline Safety & 8 & 2 & 1 & 3 \\
\hline Efficiency & 7 & & 5 & \\
\hline Appropriateness & 15 & 3 & 1 & 6 \\
\hline Continuity & 8 & 1 & 3 & 5 \\
\hline \multicolumn{5}{|l|}{ Diagnosis } \\
\hline Substance abuse & & 4 & 3 & 5 \\
\hline Mood disorder & & & & 4 \\
\hline Psychosis/Schizophrenia & & & & 2 \\
\hline Other & & & & 4 \\
\hline $\begin{array}{l}\text { Multiple diagnoses } \\
\text { encompassed }\end{array}$ & 71 & 8 & 18 & 13 \\
\hline \multicolumn{5}{|l|}{ Data source } \\
\hline Survey/Audit & & & 2 & \\
\hline
\end{tabular}




1
2
3
4
5
6
7
8
9
10
11
12
13
14
15
16
17
18
19
20
21
22
23
24
25
26
27
28
29
30
31
32
33
34
35
36
37
38
39
40
41
42
43
40
45
49
50
50
51
53
55
50

Administrative/Medical data

71

12

18

28

Multiple sources

1 8 10 


\section{Table 3. Characteristic Classifications}

Taken from McEwand and Goldner (2001), pages 37-56

\begin{tabular}{|c|c|}
\hline $\begin{array}{c}\text { Indicator } \\
\text { Characteristic }\end{array}$ & Definition \\
\hline Acceptability & $\begin{array}{l}\text { "Services provided meet expectations of service users, community, } \\
\text { providers and government." }\end{array}$ \\
\hline Accessibility & $\begin{array}{l}\text { "Ability of people to obtain services at the right place and right time } \\
\text { based on needs." }\end{array}$ \\
\hline Appropriateness & $\begin{array}{l}\text { "Services provided are relevant to service user needs and based on } \\
\text { established standards." }\end{array}$ \\
\hline Competence & $\begin{array}{l}\text { "Knowledge, skills and actions of individuals providing services are } \\
\text { appropriate to service provided." }\end{array}$ \\
\hline Continuity & $\begin{array}{l}\text { "The system is sustainable, comprehensive, and has the capacity to } \\
\text { provide seamless and coordinated services across programs, } \\
\text { practitioners, organizations, and levels of service, in accordance with } \\
\text { individual need." }\end{array}$ \\
\hline Effectiveness & "Services, intervention or actions achieve desired results" \\
\hline Efficiency & $\begin{array}{l}\text { "Organizations / programs achieve desired results with the most cost } \\
\text { effective use of resources." }\end{array}$ \\
\hline Safety & $\begin{array}{l}\text { "Organizations / programs avoid or minimize potential risks or harms } \\
\text { to consumers, families, mental health staff and the community } \\
\text { associated with the intervention / lack of intervention or the } \\
\text { environment." }\end{array}$ \\
\hline System & $\begin{array}{l}\text { "System performance measures should provide information about } \\
\text { whether the system as a whole is operating with respect to policy, } \\
\text { evaluation, governance and funding, and human resource planning." }\end{array}$ \\
\hline Program & $\begin{array}{l}\text { "Measures must be related to client outcomes with respect to core } \\
\text { programs and services such as case management, crisis response / } \\
\text { emergency service, housing, inpatient / outpatient care, consumer } \\
\text { initiatives, family self-help and vocational / educational supports." }\end{array}$ \\
\hline Client & $\begin{array}{l}\text { "At the client level, aside from information on clinical and functional } \\
\text { conditions, client satisfaction and quality of life are important issues } \\
\text { for informing and measuring the effectiveness of programs and } \\
\text { services." }\end{array}$ \\
\hline Input & $\begin{array}{l}\text { "Refers to resources put into mental healthcare and thereby relate[s] } \\
\text { to the structural or organizational characteristics of a system or } \\
\text { setting. Inputs are often expressed in terms of financial resources or } \\
\text { numbers and types of personnel, facilities, etc." }\end{array}$ \\
\hline Process & $\begin{array}{l}\text { "Relates to the key activities of a service or system in the provision } \\
\text { of care to persons with mental illness... Meaningful process } \\
\text { measures are ones where the links to client, program or system } \\
\text { outcomes are evident." }\end{array}$ \\
\hline Outcome & $\begin{array}{l}\text { "Outcomes reflect the total contributions of all those who fund, plan, } \\
\text { and provide service as well as those of clients and their families. An }\end{array}$ \\
\hline
\end{tabular}



attributed to a program / service."

* McEwan, K., \& Goldner, E. (2001). Accountability and performance indicators for mental health services and supports: A resource kit. Ottawa, ON: Health Canada.

http://seniorspolicylens.ca/Root/Materials/Adobe\%20Acrobat\%20Materials/accountabilit y_and_performance_measures_for_mental_health_services_and_supports.pdf 